\title{
DEL DANDY AL ESTETA: EL CULTIVO DE LA SENSIBILIDAD, ENTRE LO INDIVIDUAL Y LO COLECTIVO
}

Sonsoles Hernández Barbosa

Universitat Illes Balears

Data recepción: 2016/05/09

Data aceptación: 2017/04/18

Contacto autora: sonsoles_h@hotmail.com

ORCID: https://orcid.org/0000-0002-4277-0578

\section{RESUMEN}

Las figuras del dandy y el esteta, con sus características singulares, abanderaron en las urbes decimonónicas el intento de huida de una cotidianidad apegada a patrones y códigos convencionales de comportamiento. Para ello, ambas tipologías apostaron por el cultivo de una particular sensibilidad. En este artículo, nos adentraremos en las personalidades del dandy y el esteta para tratar de entender en qué consistió y a qué respondió esta sublimación de lo sensible. También revelaremos algunos de los rasgos que diferencian al dandy del esteta así como la relación de ambos con el elitismo. Finalmente, bajo este mismo prisma sociológico, se indagará en las dinámicas que hay detrás del paso de la singularidad del dandy a la aparición de todo un movimiento como el esteticismo de finales del XIX.

Palabras clave: dandy, esteta, esteticismo, fin de siglo, historia de los sentidos

\section{ABSTRACT}

The figures of the dandy and the aesthete embodied the attempt to escape the conventional behaviours, codes and standards of everyday 19th-century urban society. Despite having their own peculiarities, both dandies and aesthetes based their nonconformity on the cultivation of a singular form of sensibility. This article will explore the personalities of dandies and aesthetes in seeking to gain an understanding of what this sublimation of sensibility consisted of and what it responded to. It shall also outline some of the differences between dandies and aesthetes, while examining the relationship of both with elitism. Finally, the same sociological lens will be used to analyse the dynamics that came into play when the singular phenomenon of dandyism gave way to the full-blown intellectual movement that was aestheticism in the late $19^{\text {th }}$ century.

Keywords: dandy, aesthete, aestheticism, fin de siècle, sensory history

Las grandes ciudades decimonónicas asistieron al surgimiento de figuras que adoptaron actitudes insólitas ante la ciudad, la vida y el arte'. En concreto, el dandy y el esteta, con sus singularidades, presentan un aspecto común: el rechazo hacia una cotidianidad apegada a patrones y códigos convencionales de comportamiento. Como alternativa, ambas figuras se caracterizan por el cultivo de una particular sensibilidad que inevitablemente individualiza a estas personalidades del resto.

Si bien existieron personajes históricos que asumieron en sus comportamientos actitudes que se corresponden con la tipología del dandy y el esteta, el arquetipo de estos personajes nos ha venido legado en gran medida a través de la literatura. Muestra de lo que pudo constituir esta sensibilidad una novela representativa de la cultura 
finisecular, À Rebours (1884) de Huysmans, nos ayudará a entender las actitudes implícitas en el imaginario que rodeaba a estas figuras. Aunque el género novelístico no puede entenderse como un documento histórico que nos desvela trazas de un personaje o una situación pasada, puede adquirir un carácter documental desde el punto de vista de la historia de los imaginarios o de las representaciones². Es más, en ciertos casos, los personajes que representan al dandy o al esteta se convierten en alter-ego de los propios autores, es decir, constituyen un retrato del autor o del tipo de vida al que aspiraba; a través del personaje, el escritor expone sus propias aspiraciones vitales en el universo de ficción, lo cual le permite construir una vita aestetica en total plenitud. Se produce así un trasvase entre personaje literario y escritor, quienes pasan a identificarse mutuamente mediante la encarnación de atributos comunes. Es el caso de Wilde, autor de The Picture of Dorian Gray y quien adopta la actitud propia del dandy en la década de $1880^{3}$. Por su parte, el personaje del conde Des Esseintes, protagonista de À Rebours, se considera inspirado en la vida del aristócrata Robert de Montesquiou (1855-1921)4.

En este artículo indagaremos en las personalidades del dandy y el esteta tratando de entender a qué respondió su sublimación de la sensibilidad. A este propósito intentaremos dar respuesta a las siguientes cuestiones: ¿qué aspectos presentan en común y en qué se diferencian una y otra tipología? ¿qué elementos caracterizan esta particular sensibilidad? ¿qué relación existe, a propósito de estas figuras, entre sensibilidad y elitismo? ¿cómo interpretar el paso de la singularidad del dandy a la del desarrollo de todo un movimiento como el esteticismo?

\section{El dandy y el esteta: un acercamiento a ambos perfiles}

A pesar de los orígenes difusos del término "dandy", parece existir consenso en cuanto a su procedencia inglesa. El estilo de vida del dandy fue establecido por figuras como George "Beau" Brummell (1778-1840) y por sus imitadores directos y también por cronistas y novelistas que los retrataron. Impactó particularmente entre los jóvenes escritores y artistas así como entre los cuerpos militares caracterizados por una "deli- berada improductividad" y por un "refinamiento metódico y consumo lujoso" ${ }^{5}$. En concreto, Smith ha sintetizado la actitud del dandy - de Brummell en particular -, a través de un patrón caracterizado por elementos como el exclusivismo, el autocontrol, la indiferencia ante acontecimientos significativos o un comportamiento ceremonioso que centra la atención de la audiencia ${ }^{6}$.

El especialista en estudios teatrales Frantisek Deak establece una diferenciación entre el dandy inglés y el francés, del que surgiría el esteta. El comportamiento del dandy francés que caracterizó a Théophile Gautier, Baudelaire, Barbey d'Aurevilly y otros románticos llevaba implícito el intento de llamar la atención a través de la vestimenta. Esto formaba parte del proceso de teatralización de la cotidianeidad que Deak conceptualiza bajo el apelativo de "kaloprosopia" -o arte de la personalidad-como una característica de la dinámica existencial del artista moderno. El dandy teatralizaría la vida real en un proceso de estetización de la personalidad que abarca todas sus dimensiones, rompiendo así los límites entre lo que es y lo que no es arte?

Como parte de esta dinámica, su particular indumentaria no formaría parte sino del posicionamiento contrario a la cultura dominante propio del dandys. Con una actitud provocativa y una apariencia física más que notoria, el dandy plantea su disidencia respecto a las normas convencionales. Concentra así la crítica a la cultura materialista y a los principios del progreso, lo que responde a la afirmación de Baudelaire: "el dandy está hastiado de todo" 9 .

También en cuanto a la moral plantea una escala de valores inversa a la comúnmente establecida. Henry Wotton, el personaje que ejerce de preceptor de Dorian Gray, en The Picture of Dorian Gray (1890) de Oscar Wilde, incluso llega a desdibujar los límites entre el bien y el mal, su moralidad aparece subvertida ante la utopía compartida de una vida en plenitud ${ }^{10}$. Al adoptar este tipo de actitudes, el dandy se individualiza escandalizando a la sociedad. Es más, el fracaso en la misma deviene en el éxito propio, aunque siempre, por supuesto, cumpliendo unos mínimos requisitos de supervivencia. A su vez, el dandy también es visto con recelo por esa sociedad de la que quiere distanciarse. Su conducta de 
oposición frente al mundo se presenta así afín a la dinámica propia del arte de vanguardia.

En la evolución de la tipología del dandy, Deak señala la transición que se produce en torno al año 1880 de la figura del dandy a la del esteta"1. Tanto en Francia como en la Inglaterra victoriana de la década de 1870 adquiere importancia la figura del individuo de sensibilidad extrema y apasionado por el arte que bajo la apelación de "esteta" habían codificado los hermanos Goncourt ${ }^{12}$. El esteta, como evolución de la figura del dandy, aparece ligado a la idea de conformar una "vida para el arte" o más bien de construir la propia "vida como arte"13.

Más que despreciar el mundo o la realidad en general, lo que el esteta rechaza son las obligaciones, las convenciones, la lógica que trae implícita ${ }^{14}$. Por ello, ante el mismo hastío que siente el dandy por ciertas actividades sórdidas ligadas al universo burgués y al materialismo de la mercancía, la alternativa del esteta radica en la exaltación de la vida a través de estímulos sensibles haciendo de ésta una obra de arte (recordemos la raíz etimológica de "estética" como "aisthesis", es decir, sensación, sensibilidad). $Y$ a este respecto sí que podemos matizar una diferencia entre la tipología del dandy y la del esteta. Si la actitud propia del dandy partía de una marcada visibilización basada en la oposición a las conductas establecidas tanto en la ética como en la apariencia física pasando por los comportamientos sociales, en el caso del esteta, esta actitud se apoya en lo físico y lo performativo - la vestimenta, la apariencia -, como parte de una orientación que prioriza la búsqueda de placer sensible y que trata de hacer de la vida cotidiana un lugar para el goce de los sentidos. De este modo podemos calificar al esteta como un "buscador de sensaciones". Esta actitud es la que adopta el conde des Esseintes, protagonista de la novela À Rebours de Joris-Karl Huysmans, paradigma de hipersensibilidad, refinamiento y sensorialidad exaltada.

\section{Vita aestetica o el placer de los sentidos}

Como anunciaba, la definición del esteta venía determinada por un comportamiento vital asociado al intento de hacer de la vida una obra de arte $y$, por tanto, un espacio para el continuo placer sensible. Hemos podido extraer de este modelo de vida del esteta al menos tres tipos de recursos o actidudes que lo caracterizan:

\section{Refinamiento sensorial y apelación al artificio}

El refinamiento de los sentidos y la apelación al artificio son dos características que se encuentran estrechamente relacionadas y por ello las englobamos bajo un mismo epígrafe. Su vínculo residiría en que la capacidad para apreciar un amplio abanico de matices a través de los sentidos - ya sean de tipo visual, olfativo o sonoro -, llamaría al gusto por un tipo de objeto que respondiese a esa sutileza de estímulos.

Sin duda, entre estos objetos, la obra de arte ocupa un lugar preeminente por dar respuesta a un gusto refinado y, a este propósito, la experiencia estética polariza en buena medida el modelo de vida del esteta. En uno de los documentos más célebres de la teoría esteticista, Studies in the History of the Renaissance (1873), Walter Pater manifiesta su concepción de la experiencia estética. En particular, apunta llegado cierto momento a una visión de ésta como una relación "de fuerzas" entre el objeto y el individuo que posteriormente se transforman en impresiones. Y así, cuando:

la reflexión comienza a considerar esos objetos, éstos desaparecen bajo su influencia, la fuerza que los une queda suspendida como por arte de magia y cada objeto se desvanece en un cúmulo de impresiones -color, olor, textura- en el espíritu del observador ${ }^{15}$.

A partir de este pasaje podemos entender que en la concepción esteticista no existiría una supuesta división entre un mundo externo, físico, y una realidad interna, producto de la imaginación, sino que todo formaría parte de un mismo proceso y de una única dinámica de fuerzas ${ }^{16}$. Esta concepción de la experiencia estética otorga a los sentidos un protagonismo fundamental, en tanto que mediadores de esa relación de fuerzas entre objeto y sujeto. Puesto que los sentidos filtran la experiencia estética, la educación de los mismos en la percepción de sensaciones, su refinamiento, se convierte en una característica fundamental de la personalidad del esteta. La búsqueda del disfrute a través de una experiencia estética permanente, a la que se apela en diferentes aspectos y 
momentos de la cotidianidad - lo que se ha dado en llamar "new hedonism"17 - constituirá una característica intrínseca a la personalidad del esteta. El refinamiento en los sentidos también favorecería el vivir más intensamente cada experiencia. Este tipo de actitud permitiría superar el tedio cotidiano propio de una sociedad industrializada en la que los procesos tienden a mecanizarse ${ }^{18}$.

Encontramos un ejemplo de cómo el refinamiento sensorial del esteta desemboca en el gusto por el artificio en uno de los más jugosos pasajes de À Rebours. Esta novela constituye en su práctica totalidad una exposición, con una trama narrativa que pasa a un segundo plano, de los gustos del protagonista, el aristócrata Jean Floressas des Esseintes, quien preso de su misantropía se muda a las afueras de París a vivir la vida que desea. En su retiro en Fontenay-aux-Roses, Des Esseintes aspira a llevar una vida regida por la intensidad de sensaciones, lejos del hipócrita progresismo en el que se mueve la sociedad de su tiempo y que se encuentra en el origen de la afección nerviosa que padece. En ese gusto por lo artificial, por la creación de sensaciones, cada uno de los capítulos está dedicado a un ámbito sensorial diferente. Así, si el capítulo I está dedicado al lenguaje de los tonos y matices de los colores, el $V$ lo está al de la pintura, el $X$ al lenguaje de los perfumes, el XIV a la estética literaria y el XV al de la sensibilidad musical.

Nos interesa en particular el capítulo IV, en el que plantea una síntesis de los lenguajes musical y gustativo a través del sabor de los licores, de lo que denomina su "órgano de boca": una sucesión cilíndrica de barriles que contenían diferentes licores y bebidas alcohólicas, cada uno de ellos asociados a un sonido musical. Los barriles estarían perforados en su parte baja por un grifo y se disponían de tal manera que se encontraban conectados a una barilla. Pulsando un botón situado en la pared se activaba el dispositivo que permitía que todos los grifos abiertos llenaran de licor sus respectivos cubiletes situados debajo de cada uno de ellos. A través de la magia evocadora que le proporcionan las diversas sensaciones, Des Esseintes subvierte el orden racional de la realidad y accede a uno diferente proporcionado por su sensibilidad personal. Las sensaciones no eran nuevas pero estaban ordenadas de un modo particular, que suponía subvertir el convencionalmente establecido. Para el conde Jean Floressas Des Esseintes, la salvación no se encuentra, por tanto, en un supuesto mundo imaginario, utópico, alternativo a la realidad, sino en el trabajo con la realidad misma. La división entre el mundo real y el imaginario del artista aparecería así ontológicamente superada en su caso ${ }^{19}$. Así lo expresa Huysmans en un fragmento del que reproducimos buena parte debido a su interés:

Des Esseintes iba bebiendo una gota de aquí, otra de alli; interpretaba de este modo sinfonías interiores, que le llegaban a producir, en la garganta y en el paladar, unas sensaciones análogas a las que la música produce en el oído.

Pues, según él, el sabor de cada licor se correspondía con el sonido de un instrumento preciso. El curaçao seco, por ejemplo, contenía en su sabor el sonido del clarinete, cuyo tono es agridulce y aterciopelado; el kummel correspondía al oboe, cuyo timbre sonoro tiene una resonancia nasal; la menta y el anis, a la flauta, que es a la vez azucarada y picante, chillona y suave; el kirsch suena con la furia de la trompeta; la ginebra y el whisky arrasan el paladar con el sonido estridente del trombón y del cornetín; el aguardiente de orujo fulmina con el estrépito ensordecedor de la tuba; mientras que el raki de Chio y la almáciga retumban como el platillo y el bombo sacudidos a todo brazo, en la piel de la boca.

Pensaba también que esta asimilación podía llevarse más lejos, y que era posible formar cuartetos de instrumentos de cuerda bajo la bóveda del paladar: representando el violín por el viejo aguardiente, humoso y delicado, agudo y grácil; simulando la viola por el ron, que es más vigoroso y más zumbón; el vespetro desgarrador y prolongado, melancólico y tierno, actúa como violonchelo; el contrabajo, fuerte, sólido y oscuro, corresponde a un puro añejo bitter. Se podía incluso llegar a formar un quinteto añadiendo un quinto instrumento, el arpa, que presentaba una clara analogía con el sabor vibrante, y la nota argentina, destacada y aguda del licor seco de comino. [...]

Una vez asentados estos principios, Des Esseintes, merced a una serie de eruditas experiencias, había conseguido interpretar sobre su lengua silenciosa melodías, mudas marchas fúnebres de gran espectáculo, y escuchar en el interior de su boca solos de menta, dúos de vespetro y de ron ${ }^{20}$. 
Este pasaje pone sobre la palestra la cuestión de las relaciones intersensoriales o sinestesias (literalmente "sensación conjunta"), en un intento por despertar los diferentes ámbitos sensibles a través de analogías subyacentes entre cada uno de ellos.

En última instancia, la experiencia de Des Esseintes es física, exige un paladar refinado capaz de percibir los diferentes matices de sabores, de lo contrario sería imposible para él percibir la sinfonía gustativa. La comprensión de la experiencia estética como un fenómeno psico-fisiológico desembocó en el establecimiento de correspondencias entre los diferentes dominios de los sensorial, una de las búsquedas más empedernidas de la cultura europea del fin de siglo. Si la pintura o la música no eran tanto fenómenos intelectuales como psico-fisiológicos, producto de fuerzas que implicaban la recepción de determinadas longitudes de onda (de luz en el caso de la pintura, de sonido en el de la música), ambas disciplinas podían ser mensurabilizadas y cuantificadas y por tanto podían establecerse equivalencias o analogías mutuas. Al esteblecer equivalencias entre ámbitos sensoriales diferentes la realidad es subvertida. La sinestesia permite así disolver la dualidad entre sujeto y objeto, entre mundo real e imaginación, al conjugar lo físico con lo imaginativo.

En realidad, la cuestión de la sinestesia y de la percepción sensorial a finales de siglo se mueve entre el ámbito de lo místico, de la voluntad de escapar del materialismo mundano que encarna el protagonista de Huysmans, y el de lo fisiológico, producto de los avances científicos que se venían produciendo desde mediados de siglo en torno a la percepción de la luz, el color y el sonido ${ }^{21}$. La enfermedad nerviosa que padece el protagonista de Huysmans constituye una bisagra entre estos dos ámbitos, vinculada a los efectos fisiológicos que le produce una realidad que no puede soportar. Frente a esa realidad insufrible, la sinestesia se vuelve un eficaz antídoto.

Precisamente hacia esta línea de búsqueda del artificio se orientan también las enseñanzas que el dandy Lord Henry Wotton dirige al joven Dorian Gray en la novela de Wilde. Wotton lo conduciría a un estilo de vida semejante al que Des Esseintes, el protagonista de À Rebours, pre- tendía, advirtiéndole de que "ser natural es sencillamente una pose" 22 . Como libro de cabecera, Lord Henry va a ofrecer a Dorian lo que se ha identificado como un ejemplar de À Rebours ${ }^{23}$, novela que se había publicado siete años antes ${ }^{24}$.

\section{El recurso a la memoria afectiva}

La apelación a la memoria, a la recreación en el presente de momentos placenteros del pasado, también puede contribuir al deleite al que aspira el esteta. La memoria permitiría una continua actualización de esas experiencias. Se trata de un recurso que Proust llevará a su culmen a través del concepto de "memoria involuntaria" en À la Recherche du temps perdu (1913-1927) y en escritos posteriores. Hay que apuntar, asimismo, que la movilización de la memoria afectiva no es incompatible con la experiencia física a la que nos acabamos de referir en el punto primero, ya que es precisamente esa experiencia física lo que el recuerdo, en tanto que impresión, evoca.

Si volvemos a À Rebours, junto con la intensidad de las sensaciones, multiplicadas en la experiencia sinestésica, Huysmans consigue proporcionar a su personaje una cotidianeidad singularizada mediante el recurso a la memoria afectiva. En uno de los pasajes del capítulo XI, el protagonista decide emprender un viaje a Londres. De camino a la estación de ferrocarril que le conduce a Dieppe en la costa norte francesa, la atmósfera lluviosa evoca en él el clima típico londinense. Antes de llegar a la estación de tren hace un receso en una tasca. Allí, el vino de Oporto que degusta le sugiere las tabernas retratadas en las novelas de Charles Dickens, de modo que de forma inesperada se siente ubicado en ese preciso instante en el mismo Londres. Se pregunta entonces ¿para qué emprender un viaje que terminaría por decepcionarle? Veámoslo en palabras de Huysmans:

El tiempo tan abominable que se cernía sobre París constituía ya para él un anticipo del clima de Inglaterra, y la imagen de un Londres Iluvioso, colosal, inmenso, oliendo a hierro fundido y a hollín de fábrica, y humeando sin cesar en medio de la niebla, desfilaba ante sus ojos. Hileras de muelles se extendian hasta perderse de vista, en los que pululaban enjambres de hombres [...]. Esta atmósfera de cuerpo de guardia le produjo 
a Des Esseintes un cierto emblandecimiento; amodorrado por el parloteo de los ingleses que no dejaban de charlar entre ellos, empezó a soñar despierto, evocando, ante el color púrpura del oporto escanciado en las copas, los personajes de las novelas de Dickens a los que tanto les gustaba este vino; y su imaginación fue poblando la bodega de nuevos clientes. [...] Sintiéndose contento y feliz de estar al abrigo de las inclemencias del tiempo, se apoltronó cómodamente ante la visión de este Londres imaginario, y escuchaba el navegar de los remolcadores sobre el Támesis que bramaban de forma siniestra, cerca del puente que está por detrás de las Tullerías. [...] ¿y para qué moverse cuando uno puede viajar tan magníficamente sin tener que levantarse de la silla? ¿Acaso no se encontraba ya en Londres? ¿Acaso su atmósfera peculiar, sus olores característicos, sus habitantes, sus alimentos y sus utensilios no le rodeaban ya por todas partes? ¿Qué podía pues esperar encontrar allí sino nuevas desilusiones, como ya le había ocurrido en Holanda? ${ }^{25}$.

El protagonista señala que a lo largo de su vida sedentaria sólo se había sentido atraído por dos países: Holanda e Inglaterra. A Holanda ya se había dirigido y había vuelto decepcionado al no haber encontrado allí nada de lo que conformaban los evocadores cuadros de Rembrandt o de Teniers. Ante el temor de que lo mismo le sucediera en Inglaterra decide suspender su andadura y quedarse con el sabor de sus evocaciones mentales. Una evocación mental que nos habla del poder sugestivo de los sentidos.

\section{Una filosofía del instante y la preferencia por lo mínimo}

En el mismo texto al que me refería en el primer punto de esta sección, en el que Pater manifestaba su concepción de la experiencia estética, éste aludía, a continuación, a la duración de la misma: "lo que de real hay en ellas [las impresiones] no dura sino un instante, desapareciendo en cuanto intentamos aprisionarlo"26. Según esto, la existencia que realmente merece la pena queda reducida a nada más que a nuestras impresiones en un momento determinado. Se trataría, por tanto, de buscar la mayor profusión de estos instantes así como su máxima intensidad.
Dentro de esta filosofía de lo pequeño, del momento, uno de los elementos que destacaremos a la hora de plantear una vida que vale la pena ser vivida es la atención que el esteta presta a los pequeños detalles; detalles mínimos que tienen que ver con la vida cotidiana: desde hacerse el nudo de la corbata hasta elegir el tipo de pañuelo que debe llevar en el bolsillo de la chaqueta ${ }^{27}$. Del mismo modo, aspectos de la vida cotidiana como la comida o la bebida no son vistos como mera alimentación sino como fuente de estimulación sensorial.

La precisión y la meticulosidad con que Des Esseintes construye su vida cotidiana se corresponde asimismo con la concienzuda tarea de Huysmans a la hora de desarrollar algunos aspectos de su novela, por ejemplo, detallando los nombres de los diferentes platos dickensianos que el conde degusta. De hecho, el propio Huysmans se refería a su novela como un trabajo de precisión ${ }^{28}$. Se produce así irremediablemente una simpatía o sinergia entre la actitud del personaje y la del escritor que le da vida. Por otra parte, estos detalles aproximan el texto a una novela realista, de la que en principio escapaba la (no)trama principal, orientada ya no a la narración sino al relato del peculiar estilo de vida del protagonista.

Precisamente esta filosofía del detalle diferencia al esteta de otras tipologías sociales que emplean la apariencia física como modo de singularizarse. Así, lo que a finales del siglo XIX el sociólogo Thorstein Veblen denominó "clase ociosa" - aquellas capas de la sociedad que ostentan un estatus social más alto: la clase intelectual, gobernante, religiosa y de deportistas de élite - se caracterizaría al igual que el dandy por el empleo de hábitos de vida refinados ${ }^{29}$, el consumo de bienes de excelencia que identificarían a sus miembros como connaisseurs - lo cual pasaría por el desarrollo de un gusto exquisito ${ }^{30}$ - y un tipo de vestimenta singular:

gran parte del encanto atribuido al zapato de charol, a la ropa blanca impoluta, al sombrero de copa brillante y al bastón, que realzan en tan gran medida la dignidad natural de un caballero, deriva del hecho de que sugieren sin ningún género de dudas que el usuario no puede, así vestido, echar una mano a ninguna tarea que sirva de modo directo e inmediato a ninguna actividad humana 
útil. Los vestidos elegantes sirven a su finalidad de elegancia no sólo por ser caros, sino también porque constituyen los símbolos del ocio ${ }^{31}$.

Sin embargo, el dandy y el esteta se diferencian de esta clase ociosa al no compartir con ella el "derroche ostensible" 32 como norma del vestir. Precisamente, el esteta marca la diferencia en su modo de vestir a través del detalle aislado diferenciador. Así también, tanto el dandy como el esteta renuncian al atributo de clase, tratando de distanciarse de una asignación o un estatus social determinado.

Las tres características apuntadas hacen del esteta una figura anclada de lleno en la modernidad. Por un lado, no podemos obviar que la filosofía del instante se presenta estrechamente conectada con la experiencia de la vida moderna que, como Baudelaire había asentado en Le Peintre de la vie moderne ${ }^{33}$, se caracteriza por la fugacidad y la contingencia de las sensaciones frente a la universalidad de las categorías históricas imperantes hasta el momento. Por otro, la modernidad de las tipologías del dandy y el esteta radica en una comprensión del ser humano que ya no parte de una supuesta esencia radicada en un ente bien espiritual o bien psíquico, sino que contempla tanto el modo en que el individuo se exhibe públicamente como la construcción que de él hace la sociedad ${ }^{34}$.

\section{Lo individual y lo colectivo: de la singu- laridad del esteta al movimiento esteticista}

En esta última sección nos adentraremos en cuestiones de tipo sociológico, en particular, abordaremos las dinámicas que subyacen al paso de la singularidad de la figura del dandy a la aparición de todo un movimiento como es el esteticismo. En efecto, durante las dos últimas décadas del siglo XIX el movimiento esteticista con origen en la Inglaterra victoriana, retoma los principios que en torno al arte habían desarrollado nombres vinculados al romanticismo francés como Gautier - Baudelaire, quienes se habían opuesto tanto a la tradición del arte burgués como del arte social a través de la defensa de la doctrina de l'art pour I'art ${ }^{35}$. Así, la publicación en 1882 por parte del escritor Walter Hamilton de su estudio seminal The Aesthetic Movement in England supone la identificación de un nuevo movimiento estético en el que se dan cita pintores, decoradores, arquitectos, artesanos, poetas bajo un aspecto común: su alzamiento contra la convención materialista en favor del placer sensible. Ese mismo año la escritora Lucy Crane exhortaba a su audiencia a buscar la belleza en los más mínimos aspectos de la vida cotidiana. Su intervención sugiere hasta qué punto el esteticismo se había convertido a principios de la década de 1880 en una influencia común, a pesar de las controversias que estaba empezando a generar. El hecho de que los confines del esteticismo llegasen incluso a mujeres escritoras probaría la extensión de los límites del movimiento ${ }^{36}$. A partir de 1890 el esteticismo y con él la figura del esteta entran en declive. No obstante, la extensión de las críticas contra el esteta por parte de autores como Max Nordau y, en prensa, a través de caricaturas como las de Georges du Maurier en el diario Punch (1874-1882), son muestra de la popularidad que alcanzó el movimiento ${ }^{37}$.

Para entender el paso de la figura singularizada del dandy a la aparición de todo un movimiento como el esteticismo tenemos que ubicar dónde se sitúan ambos respecto al vínculo entre estética y sociedad. Así, esta relación discurre entre dos polos antagónicos: el que establece un estrecho nexo entre estética y sociedad, en el que se sitúa el dandy, por un lado, y por otro, el que lo niega, el esteticismo, que plantea una estética al margen de lo social ${ }^{38}$. Aunque pudiera parecer lo contrario, que es en el planteamiento vital del dandy en el que se produce un distanciamiento de lo social y que, en cambio, en el desarrollo de todo un movimiento como el esteticismo la relación arte y sociedad se hace extensiva, lo cierto es que si nos aproximamos a las dinámicas internas de cada uno de los fenómenos apreciamos una actitud vital que gira en torno a la singularización social a través de la imagen en el caso del dandy y de alejamiento de la sociedad de los principios que rigen el esteticismo.

Por un lado, el dandy plantea la voluntad de significarse socialmente a través de elementos sensibles. Esto supone el desarrollo del culto a un tipo de personalidad que marca su diferenciación frente a la clase burguesa -o la "clase ociosa" a la que se refiere Veblen- a través de la apariencia física. De este modo, queda definido por la sin- 
gularidad, por la distinción frente a los modos de actuación dominantes en la sociedad. Se produce así una relación entre sensibilidad y elitismo en tanto que la estética, la imagen, reflejo de una condición social determinada, es empleada como marqueur social. Hablaríamos, por tanto, de una fisiología en la que se hace imposible comprender su dimensión social al margen de su dimensión estética ${ }^{39}$.

Frente a una movilización de la estética con vías a la significación social, los principios que rigen la actitud esteticista reivindican, contrariamente, que el elemento estético debe presentarse con total desapego respecto a la sociedad. El esteta buscaba, veíamos, crear una cotidianidad singular, propia, subvirtiendo los elementos de la realidad y orientándola hacia el placer de los sentidos. Esta nueva cotidianidad es asumida como una obra de arte, en una dinámica común al arte de vanguardia; la subversión del orden establecido implica el establecimiento de unas leyes específicas, las leyes del arte, que se rebelan contra la convención.

Este planteamiento se hará extensivo con el movimiento esteticista, que supone la aplicación a la creación artística de los principios apuntados como rectores de la vida del esteta. El paradigma esteticista, de este modo, trata de escapar a todo componente ideológico, ya sea el propio de las convenciones burguesas imperantes como aquél de cariz social. En el caso de las artes plásticas, esto implica a nivel de resultado pictórico el desplazamiento del interés del lienzo desde el tema, el objeto representado, a través del cual se actualiza de manera más evidente la carga ideológica, hacia polos de atracción vinculados a la sensibilidad, que tienen que ver con los elementos formales y de color, liberando así a la obra de arte de ataduras sociales, morales e institucionales. El ideal esteticista constituye de este modo un paso más en el proceso de autonomía artística emprendido por la pintura, que cristaliza formal e ideológicamente en el paradigma ut pictura musica, es decir, "como la música, la pintura", que propugna la sustitución del paradigma literario, ut pictura poesis ("como la poesía, así ha de actuar la pintura").

La música se sitúa en la cima del olimpo de las artes puesto que, alejada de la imitación, con la excepción de las formas de arte programático, su contenido se reduce a la pura forma, principio al que aspiran el resto de las artes. Así, declara Walter Pater:

una [disciplina artística] debe ser capaz de trascender su lenguaje específico y convertirse, en cierta medida, en otro arte a través de aquello que los críticos alemanes denominan Anders-streben, $y$ que podría definirse como la superación parcial de sus limitaciones; gracias a este fenómeno, las artes, sin llegar a reemplazar unas a otras, se confieren mutuamente nuevas energías [...] Todas las artes comparten el anhelo de encontrar el principio de la música, que es el arte idealmente más perfecto y completo, el objeto de la gran Anders-streben de todas las artes, de todo lo que es artístico o participa de alguna cualidad artística. Todas las artes aspiran constantemente al estado de la música. [....] Y la música es la manifestación artística que alcanza con mayor perfección ese ideal, esa identificación total de materia y forma. El fin no se distingue de los medios, ni la forma de la materia, ni el tema de la expresión: todos se entremezclan y completan entre si; y alcanzar esa perfección debe ser el anhelo de todas las artes ${ }^{40}$.

Esta declaración hay que entenderla en el marco de una de las prácticas más extendidas que afectó a la creación artística de las diferentes artes (pintura, literatura, música) de finales del siglo XIX y a la que ya nos hemos referido: la de la sinestesia. En el campo artístico, la práctica de la sinestesia implica la superación de los límites de los ámbitos convencionalmente asignados a cada una de las artes buscando establecer puentes entre ellas, lo que condujo a los pintores, por ejemplo, a buscar una "pintura musical" y a los poetas a "hacer música con palabras". En el caso de la pintura, la sinestesia iba de la mano del distanciamiento en la representación de un tema en favor de la reivindicación de las cualidades puramente plásticas, para lo cual la música absoluta se convertía en modelo ${ }^{41}$.

La comprensión de las dinámicas que rigen la evolución de la singularidad del dandy a la colectividad del movimiento esteticista exige entender el posicionamiento del esteta como punto intermedio. Si en el caso del dandy veíamos que su individualización cristaliza por oposición a la sociedad, con ésta como telón de fondo, 
singularizándose ante ella a través del culto a la personalidad, la actitud moral y la apariencia física, en el esteta, su individualización se orienta hacia el cultivo de una sensibilidad personal. Según hemos visto, esto se produce mediante el refinamiento sensorial, el gusto por el artificio, la memoria afectiva y el interés por el detalle. Es, por tanto, a través del juego con los elementos sensibles como el esteta subvierte la realidad y se construye una alternativa, orientada a seducir a sus sentidos, para lo cual la movilización de la sinestesia constituye una eficaz herramienta. El cultivo de los valores sensibles es retomado en la extensión de los principios que rigen la cotidianidad del esteta que supone el esteticismo. Así, en el marco de este movimiento, la obra de arte no es deudora de nada más que de sí misma, de los valores sensibles - plásticos y formales - que trae implícita, lo cual, en el ideario esteticista, haría de ella un ente autónomo ${ }^{42}$. 


\section{NOTAS}

1 Junto con las figuras que trataremos, otras tipologías de individuos surgidas a lo largo del siglo XIX serían el flâneur, el bohemio, el maldito o el Narciso.

${ }^{2}$ La novela decimonónica ha sido empleada como fuente de investigación histórica, por ejemplo, en cuanto al conocimiento de las dinámicas sociales de una época. Es, sobre todo, el caso de À la Recherche du temps perdu, movilizada por René Girard y Barbara Carnevali a propósito del conocimiento antropológico de las costumbres y comportamientos ("moeurs"). Cfr. B. Carnevali, "'Être, c'est être perçu'. Ce que Proust enseigne à la philosophie sociale" en Le travail de la littérature. Usages du littéraire en philosophie (D. Lorenzini y A. Revel, eds.), Rennes, Presses Universitaires de Rennes, 2012, p. 42; Carnevali, "L'observatoire des moeurs. Les coutumes et les caractères entre littérature et morale" en Pensée morale et genres littéraires. De Montaigne à Genet (JeanCharles Darmon y Philippe Desan, eds.), Paris, Presses Universitaires de France, 2009, pp. 159-178). A este respecto Girard alude al concepto de "verité romanesque", según el cual existiría una "filosofía que piensa a través de representaciones" y que da a conocer ciertos fenómenos que escapan a la reflexión conceptual propia de la filosofía. Cfr. Carnevali, "Proust philosophe du prestige" en Proust et la philosophie aujourd'hui (M. Carbone y E. Sparvoli, eds), Pisa, ETS, 2008, p. 310.

${ }^{3} \mathrm{Cfr}$. A. Adut, "Victorians, Homosexuality, and the Fall of Oscar Wilde", American Journal of Sociology, vol. 111, n. 1 (julio 2005), p. 227.

${ }^{4}$ Cfr. Th. S. Smith, "Aestheticism and Social Structure: Style and Social Network in the Dandy Life", American Sociological Review, vol. 39, n. 5 (octubre 1974), p. 733.

${ }^{5}$ Ídem, p. 727.

${ }^{6}$ Ídem, p. 731.

${ }^{7}$ Cfr. F. Deak, Symbolist theater: the formation of an avant-garde, Baltimore; London, Johns Hopkins University Press, 1993, p. 254. Nombres como los siguientes también son comúnmente vinculados al dandismo: Joséphin Pé- ladan, los escritores Édouard Dujardin, Teodor de Wyzewa y Oscar Wilde, el pintor James Whistler, así como los músicos Claude Debussy e, incluso, Maurice Ravel. En relación con el perfil dandy de este último, consúltese: M. J. Puri, "Dandy, Interrupted: Sublimation, Repression, and Self-Portraiture in Maurice Ravel's Daphnis et Chloé (1909-1912)", Journal of the American Musicological Society, vol. 60, n. 2 (verano 2007), pp. 317-372.

${ }^{8}$ Cfr. K. Humphreys, "Barbey, Baudelaire, and the 'Imprévu': Strategies in Literary Dandyism", Modern Language Studies, vol. 29, n. 1 (primavera 1999), p. 64.

${ }^{9} \mathrm{Cfr}$. Ch. Baudelaire, Los Paraísos artificiales, en Obras Completas (Javier del Prado y José A. Millán Alba, eds.), Madrid, Espasa Calpe, 2000, p. 1378.

${ }^{10} \mathrm{Cfr}$. M. Fritz, "Utopian Experimentation and Oscar Wilde's The Picture of Dorian Gray", Utopian Studies, vol. 24, n. 2 (2013), p. 291.

11 Si bien Badetz establece la cronología del movimiento esteticista, en Inglaterra, entre 1860-1890. Cfr. Y. Badetz, "Aesthetic movement et arts décoratifs ou les composants d'un style" en Beauté, morale et volupté dans l'Angleterre d'Oscar Wilde [catálogo de la exposición "Belleza, moral y voluptuosidad en la Inglaterra de Oscar Wilde", organizada por el Victoria \& Albert Museum de Londres y los Fine Arts Museums de San Francisco, en colaboración con el Museo d'Orsay de París], Paris, Flammarion, 2011, p. 35.

12 Ídem, p. 35. No obstante, la denominación de "Aesthetic Movement" es atribuida a Walter Hamilton, a partir de su texto The Aesthetic Movement in Englad. The Aesthetic Mouvement in England, London, Reeves and Turner, 1882.

${ }^{13}$ Tenemos que enmarcar esta actitud "vitalista" del esteta en un contexto marcado por la aparición desde la filosofía de posturas que reivindican este tipo de prácticas o posicionamientos. Es el caso del F. Nietzsche de La Gaya ciencia (1882), texto donde considera la creatividad un medio de reafirmación de la vida, y de Wilhelm Dilthey (18331911), quien da cuerpo al concepto de "vivencia" ("Erlebnis") como cuestión central de su filosofía.

${ }^{14}$ Cfr. P. Fox, "Dickens À La Carte: Aesthetic Victualism and the Invigoration of the Artist in Huysman's Against Nature" en Art and Life in Aestheticism. De-Humanizing and Re-Humanizing Art, the Artist, and the Artistic Receptor (Kelly Comfort, ed.), Houdmills, Basingstoke, Hampshire; New York, Palgrave, 2008, p. 66.

15 Véase: W. Pater, "Conclusión" [1868], en El Renacimiento. Estudios sobre arte y poesía (Marta Salís, trad.), Barcelona, Alba editorial, 1999, p. 226.

${ }^{16} \mathrm{Cfr}$. Fox, "Dickens À La Carte...", p. 73.

${ }^{17}$ Véase, por ejemplo, Fritz, "Utopian Experimentation...", p. 291.

${ }^{18}$ Otro de los medios para obtener experiencias más intensas como medio de estimulación creativa es el de los paraísos artificiales, tradicionalmente asociados a figuras del romanticismo literario cuando, tras las Confessions of an English Opium-Eater (1821) de Thomas de Quincey, alcanzan su apogeo en la cultura decimonónica de la primera bohemia parisina. Así, Baudelaire, Delacroix, Nerval y Gautier fueron asiduos del Club des Hachichins, del que este último dejó testimonio en su artículo "Le Club des Hachichins". Posteriormente Baudelaire publicaría dos textos sobre el alcohol y los halucinógenos: Du vin et $d u$ haschisch, redactado en 1851, y el conocido como Les Paradis artificiels, de 1857, que incluye el poema del hachish y "Un Mangeur d'opium".

${ }^{19}$ Encontramos esta lectura en Fox, "Dickens À la Carte...", pp. 66-67.

${ }^{20} \mathrm{Cfr}$. J.-K. Huysmans, A contrapelo [1884] (Juan Herrero, ed.), Madrid, Cátedra, 2000, pp. 171-172.

${ }^{21}$ Véase: S. Hernández Barbosa, Sinestesias. Arte, literatura y música en el Paris fin de siglo (1880-1900), Madrid, Abada editores, 2013.

${ }^{22} \mathrm{Cfr}$. O. Wilde, El retrato de Dorian Gray [1891] (Julio Gómez de la Serna, trad. y notas), Barcelona, Planeta, 1983, p. 53. p. 74 .

${ }^{23} \mathrm{Cfr}$. Fox, "Dickens À La Carte...", ${ }^{24} \mathrm{Cfr}$. Wilde, El retrato..., pp. 183185. 
${ }^{25} \mathrm{Cfr}$. Huysmans, À contrapelo..., pp. 261-272.

${ }^{26}$ Cfr. Pater, "Conclusión...", p. 227.

27 Según Barbara Carnevali este interés por el detalle constituye precisamente un rasgo característico del dandy, quien hace de ello un elemento fundamental de su estilo de vestir. El nudo de la corbata, por ejemplo, podría llevar a Brummell horas de preparación. Cfr. Carnevali, "Le maniérisme snob", Critique, vol. 1, número titulado "Du Style!" (M. Macé, ed.) (2010), p. 94.

${ }^{28} \mathrm{Cfr}$. Fox, "Dickens À La Carte!...", pp. 63-64.

${ }^{29} \mathrm{Cfr}$. Th. Veblen, Teoría de la clase ociosa [1899], México; Buenos Aires: Fondo de cultura económica, 1944, p. 56.

${ }^{30}$ Ídem, p. 81.

31 Ídem, pp. 176-177.

32 Ídem, pp. 178-179.

${ }^{33} \mathrm{Cfr}$. Ch. Baudelaire, El pintor de la vida moderna [1863], en Obras Completas..., pp. 1369-1417.

${ }^{34}$ Esta concepción del ser humano moderno se encontraría en consonancia con la que plantea Foucault inspirándose en Baudelaire: "no es el hombre que huye para indagar en su interior, para conocer sus secretos, su verdad oculta, sino el que trata de inventarse a sí mismo" (traducción de la autora). Cfr. G. Longford, "'Sensitive Killers, Cruel Aesthetes, and Pitiless Poets': Foucault, Rorty, and the Ethics of SelfFashioning", Polity, vol. 33, n. 4 (verano 2001), p. 573.

35 Respecto a la doctrina del arte por el arte, véase, por ejemplo, la siguiente bibliografía: N. A. Roth, "'L'artiste' and 'I'art pour l'art': the new cultural journalism in the july monarchy", Art journal, vol. 48, n. 1, volumen titulado "Nineteenth-century French art institutions" (primavera 1989), pp. 35-39; A. Cassagne, La théorie de l'art pour l'art en France chez les derniers romantiques et les premiers réalistes [1906], Seyssel, Champ Vallon, 1997; P. Bourdieu, Las reglas del arte: Génesis y estructura del campo literario [1992], Barcelona, Anagrama, 2002.

${ }^{36}$ Cfr. M. Joannou; C. Nicholson, "General Introduction", en The Women Aesthetes: British Writers, 1870-1900. Vol. I, 1870-1880 (Maroula Joannou y Claire Nicholson, eds.), London, Pickering and Chatto, 2013, pp. vii, ix. No obstante, en el caso de mujeres como Lucy Crane, algunos de los principios del esteticismo que adopta contradicen postulados propios del esteta. Su convicción, por ejemplo, heredera de William Morris, de que la belleza de un objeto se presenta asociada a su funcionalidad la alejaría de todo hedonismo. Joannou, "General Introduction...", p. viii.

${ }_{37}$ Cfr. M. Nordau, Degeneration [Entartung, 1892], New York, Appleton and Company, 1895, p. 319 y ss.

${ }^{38}$ El caso del dandy se enmarcaría dentro de lo que Carnevali, por oposición a la idea de autonomía estética, denomina "estética social". Cfr. Carnevali, "L’Esthétique sociale entre philosophie et sciences sociales", Tracés. Revue de sciences humaines, vol. 13 (número especial) (2013), pp. 29-48.
${ }^{39}$ Cfr. Carnevali, "'Être, c'est être perçu'. Ce que Proust enseigne à la philosophie sociale", en Le travail de la littérature. Usages du littéraire en philosophie (D. Lorenzini y A. Revel, eds.), Rennes, Presses Universitaires de Rennes, 2012, pp. 46-47.

${ }^{40} \mathrm{Cfr}$. Pater, "Conclusión...", pp. 140-145.

${ }^{41}$ Cfr. Hernández Barbosa, Sinestesias...

${ }^{42}$ Como ya expusimos en otro texto, la cuestión de la autonomía debe ser entendida, más en el plano teórico y programático que como realidad, según había intuido el propio Nietzsche, al entender el planteamiento esteticista como la aporía de la "serpiente que se muerde la cola": por un lado proclama la autonomía del arte y por otro reprocha a la sociedad su falta de comprensión de aquello en lo que este consiste auténticamente, la forma pura. Véanse al respecto: É. Michaud, "Autonomie et distraction", en Histoire de l'art. Une discipline à ses frontières, Paris, Editions Hazan, 2005, pp. 26-27) y E. Buch, "Réévaluer I'histoire de l'avant-garde musicale", en Réévaluer l'art moderne et les avant-gardes (Esteban Buch, Denys Riout y Philippe Roussin, eds.), Paris, Éditions de l'EHESS, 2010, pp. 99-103. Asimismo, en el planteamiento vital del esteta esta supuesta autonomía que da la espalda a la realidad no tiene lugar pues, como Fox ha señalado, la cotidianeidad alternativa del esteta se configura a partir de los elementos de la propia realidad; no debe, por tanto, entenderse como un paraíso interior que únicamente apela a la imaginación. 
Del dandy al esteta: el cultivo de la sensibilidad, entre lo individual y lo colectivo

\section{REFERENCIAS}

Adut, Ari. 2005. "Victorians, Homosexuality, and the Fall of Oscar Wilde." American Journal of Sociology 111, no. 1 (July): 213-248. https:// doi.org/10.1086/428816

Badetz, Yves. 2011. "Aesthetic movement et arts décoratifs ou les composants d'un style." In Beauté, morale et volupté dans l'Angleterre d'Oscar Wilde [catalog of the exhibition "The Cult of Beauty: The Aesthetic Movement 1860 - 1900", Victoria \& Albert Museum, London, 2011], 34-43. Paris: Flammarion.

Baudelaire, Charles. 2000. El pintor de la vida moderna [1863]. In Obras Completas, ed. and trans. by Javier del Prado and José A. Millán Alba, 1369-1417. Madrid: Espasa Calpe.

Baudelaire, Charles. 2000. Los Paraísos artificiales. In Obras Completas, ed. and trans. by Javier del Prado and José A. Millán Alba, 693852. Madrid: Espasa Calpe.

Bourdieu, Pierre. 2002. Las reglas del arte: Génesis y estructura del campo literario [1992], trans. by Thomas Kauf. Barcelona: Anagrama.

Buch, Esteban. 2010. “Réévaluer I'histoire de I'avant-garde musicale." In Réévaluer l'art moderne et les avant-gardes, ed. by Esteban Buch, Denys Riout and Philippe Roussin, 85103. Paris: Éditions de l'EHESS.

Carnevali, Barbara. 2008. "Proust philosophe du prestige." In Proust et la philosophie aujourd'hui, edited by M. Carbone and E. Sparvoli, 305-322. Pisa: ETS.

Carnevali, Barbara, 2009. "L'observatoire des moeurs. Les coutumes et les caractères entre littérature et morale." In Pensée morale et genres littéraires. De Montaigne à Genet, edited by Jean-Charles Darmon and Philippe Desan, 159-178. Paris: Presses Universitaires de France.

Carnevali, Barbara. 2010. "Le maniérisme snob." Critique 1, vol. entitled "Du Style!", edited by Marielle Macé: 90-103.

Carnevali, Barbara. 2012. "'Être, c'est être perçu.' Ce que Proust enseigne à la philosophie sociale." In Le travail de la littérature. Usages du littéraire en philosophie, edited by D. Lo- renzini and A. Revel, 39-51. Rennes: Presses Universitaires de Rennes.

Carnevali, Barbara. 2013. "L'Esthétique sociale entre philosophie et sciences sociales." Tracés. Revue de sciences humaines 13 (special issue): 29-48.

Cassagne, Albert. 1997. La théorie de l'art pour l'art en France chez les derniers romantiques et les premiers réalistes [1906]. Seyssel: Champ Vallon.

Deak, Frantisek. 1993. Symbolist theater: the formation of an avant-garde. Baltimore; London: Johns Hopkins University Press.

Fox, Paul. 2008. “Dickens À La Carte: Aesthetic Victualism and the Invigoration of the Artist in Huysman's Against Nature." In Art and Life in Aestheticism. De-Humanizing and Re-Humanizing Art, the Artist, and the Artistic Receptor, edited by Kelly Comfort, 62-75. Houdmills, Basingstoke, Hampshire; New York: Palgrave.

Fritz, Morgan. 2013. "Utopian Experimentation and Oscar Wilde's The Picture of Dorian Gray." Utopian Studies 24, no. 2: 283-311. https:// doi.org/10.5325/utopianstudies.24.2.0283

Hamilton, Walter. 1982. The Aesthetic Movement in Englad. The Aesthetic Mouvement in England [1882]. London: Reeves and Turner.

Hernández Barbosa, Sonsoles. 2013. Sinestesias. Arte, literatura y música en el París fin de siglo (1880-1900). Madrid: Abada.

Humphreys, Karen. 1999. "Barbey, Baudelaire, and the 'Imprévu': Strategies in Literary Dandyism." Modern Language Studies 29, no. 1 (Spring): 61-80. https://doi. org/10.2307/3195360

Huysmans, Joris-Karl. 2000. A contrapelo [1884], ed. and trans. by Juan Herrero. Madrid: Cátedra.

Joannou, M.; Nicholson, C. 2013. "General Introduction." In The Women Aesthetes: British Writers, 1870-1900. Vol. I, 1870-1880, edited by Maroula Joannou and Claire Nicholson, viixxxii. London: Pickering and Chatto.

Longford, Graham. 2001."'Sensitive Killers, Cruel Aesthetes, and Pitiless Poets': Foucault, Rorty, and the Ethics of Self-Fashioning." Polity 
33, no. 4 (Summer): 569-592. https://doi. org/10.2307/3235517

Michaud, Éric. 2005. Histoire de l'art. Une discipline à ses frontières. Paris: Editions Hazan.

Nordau, Max. 1895. Degeneration [1892]. New York: Appleton and Company.

Pater, Walter. 1999. "Conclusión." [1868] In El Renacimiento. Estudios sobre arte y poesía, trans. by Marta Salís. Barcelona: Alba editorial.

Puri, Michael J. 2007. "Dandy, Interrupted: Sublimation, Repression, and Self-Portraiture in Maurice Ravel's Daphnis et Chloé (19091912)." Journal of the American Musicological Society 60, no. 2 (Summer): 317-372. https:// doi.org/10.1525/jams.2007.60.2.317
Roth, Nancy Ann. 1989. ' 'L'artiste' and 'I'art pour l'art': the new cultural journalism in the july monarchy." Art journal 48, no. 1, issue entitled "Nineteenth-century French art institutions" (Spring): 35-39.

Smith, Thomas. S. 1974. "Aestheticism and Social Structure: Style and Social Network in the Dandy Life." American Sociological Review 39, no. 5 (October): 725-743. https://doi. org/10.2307/2094317

Veblen, Thorstein. 1944. Teoría de la clase ociosa [1899], trans. by Vicente Herrero. México; Buenos Aires: Fondo de Cultura Económica.

Wilde, Oscar. 1983. El retrato de Dorian Gray [1891], ed. and trans. by Julio Gómez de la Serna. Barcelona: Planeta. 